\title{
EXPLORING CONTROLLED EXPERIMENTAL SETTINGS FOR LEAN CONSTRUCTION RESEARCH
}

\author{
Amila N. Wickramasekara1, Vicente A. Gonzalez², Michael O'Sullivan³, Cameron \\ G. Walker ${ }^{4}$ and Mohammed A. Abdelmegid ${ }^{5}$
}

\begin{abstract}
In recent years, an increasing number of research articles have been published to demonstrate the benefits of applying Lean tools using different approaches within the construction domain. However, there is a need to enhance the effectiveness of Lean Construction (LC) research by incorporating it within a controlled experimental environment. Due to the fact that many compound effects impact on the variable(s) of interest, it is challenging to develop controlled experiments in real construction projects. This controlled experimental environment can be achieved by developing a Serious Game-based Experimental Setting (SGES) for construction. For this paper, a literature review was conducted to identify synergies between the Agile Project Management (APM), Design Thinking, Lean Start-up and Design Science Research Methodology (DSRM) for establishing effective SGESs for construction management. We found that little research used Serious Games to establish controlled experiments for construction management. In conclusion, we propose 7 research questions to guide the development of SGESs for construction project management research in future.
\end{abstract}

\section{KEYWORDS}

Lean construction, design science, integration, collaboration, experiments.

\section{INTRODUCTION}

According to a review of recent Lean Construction (LC) literature in relation to the development of artifacts, such as conceptual frameworks, it is clear that researchers are using different technologies and processes, such as reliable commitment modelling (González et al. 2010), building information modelling (Sacks et al. 2013) and computer simulation (Abdelmegid et al. 2019) with Lean tools, such as the Last Planner® System.

1 PhD Student, Department of Civil and Environmental Engineering, The University of Auckland, Auckland, New Zealand, awic135@ aucklanduni.ac.nz, orcid.org/0000-0002-4964-3539

2 Associate Professor, Department of Civil and Environmental Engineering, Founder and Research Lead Smart Digital Lab, The University of Auckland, 20 Symonds Street, Auckland, New Zealand, v.gonzalez@auckland.ac.nz, orcid.org/0000-0003-3408-3863

3 Senior Lecturer, Department of Engineering Sciences, The University of Auckland, Auckland, New Zealand, michael.osullivan@auckland.ac.nz, orcid.org/0000-0002-5621-4206

4 Associate Professor, Department of Engineering Sciences, The University of Auckland, Auckland, New Zealand, cameron.walker@ auckland.ac.nz, orcid.org/0000-0003-3176-9341

5 Professional Teaching Fellow, Department of Civil and Environmental Engineering, The University of Auckland, New Zealand, m.abdelmegid@auckland.ac.nz, orcid.org/0000-0001-6205-570X 
Also, it can be noted that effectiveness of such artifacts has not been tested in controlled experimental environments.

On the other hand, research groups who propose new artifacts in various domains, including disaster preparedness (Feng et al. 2020), IT education (Montes et al. 2021), and project management (Rumeser and Emsley 2019), have been using controlled experiments with serious games to improve the accuracy of research findings. The goal of a controlled experiment is to manipulate the variable(s) of interest while controlling all other variables that exist in the experimental environment (Pelcin 1997). However, within the LC literature, no research has been found that utilized controlled experiments with serious games. Therefore, we argue that the validity of LC research can be enhanced by introducing controlled experimental environments with serious games for LC research. Many outside factors, such as weather, work performance and supply fluctuations (AbouRizk et al. 2011), influence construction operations and impact on the variable(s) of interest, so it is challenging to develop controlled experiments in real construction projects. Therefore, we propose the use of a Serious Game-based Experimental Setting (SGES), in which features of a real construction project can be presented, controlled and replicated (to a certain extent), in order to conduct controlled experiments.

In order to utilize serious games within experimental settings for LC research, there is a need for an appropriate research methodology. Koskela (2008) argues that construction management is a form of design science because it helps to solve industryrelated problems while contributing to knowledge. Also, Jarvinen (2004, as cited in Koskela, 2008) states that if a research question contains one of the terms design, build, change, improve, develop, enhance, maintain, extend, correct, adjust or introduce, the associated research can be considered to be design science research. Therefore, we argue that the Design Science Research Methodology (DSRM) can be an appropriate research method for LC research intending to develop artifacts. Peffers et al. (2007) presented a framework for DSRM that consists of six major phases: (1) problem identification and motivation; (2) defining the objectives for a solution; (3) design and development; (4) demonstration; (5) evaluation; and (6) communication. An artifact of the research is created during the $3^{\text {rd }}$ phase, during which a serious game can be developed for better representation of the artifact (Mateevitsi et al. 2008). Serious games can be used to demonstrate the applicability of the artifact not only for the $3^{\text {rd }}$ phase, but also for the $4^{\text {th }}$ and $5^{\text {th }}$ phases. A serious game can also be used to evaluate that artifact by using experiments and incorporating user engagement (Kato and de Klerk 2017). There are explicit synergies between serious games and DSRM towards the development of SGES.

Accordingly, the objective of this paper is to explore theoretically the development of a framework to setup SGESs, supported by the integration of Design Thinking, Lean Statup and Agile Project Management (APM) with Design Science Research Methodology (DSRM). To discover the existing relationships between these concepts, a literature review was carried out as the research method within the Scopus database using combinations of the following keywords: "controlled experiments," "design thinking," "lean start-up," "agile," and "design science research methodology" within the titles, abstracts, and keywords. Also, forward and backward snowballing of references were used to ensure inclusivity of the results. This is an exploratory conceptual paper, and as such, we haven't stated a method as logic rationing has been applied to literature findings with no data analysis (i.e.,Torp et al. 2018). 


\section{LITERATURE REVIEW}

In this section, we briefly introduce APM, Design Thinking, Lean Stat-up, serious games and DSRM, and report previous research on the available integrations of some of these processes. The aim is to emphasize the advantages of using those approaches in combination, which is useful for the efficient development of SGES, and facilitates conducting controlled experiments in the virtual environment with regards to LC artifacts.

\section{Agile Project Management (APM)}

APM is the best option in low-volume, high-variety, and highly dynamic environments (Mostafa et al. 2016). APM is based on 4 values and 12 principles (Beck et al. 2001). Agile places value on: (1) individuals and interactions over processes and tools; (2) working software over comprehensive documentation; (3) customer collaboration over contract negotiation, and (4) responding to change over following a plan. In addition, there are a number of principles that support the Agile values, including: place the highest priority on satisfying the customer through early and continuous delivery of valuable software, welcome changing requirements even late in development, deliver working software frequently from a couple of weeks to a couple of months with a preference for the shorter timescale, convey information effectively to and within a development team using face-to-face conversations, use working software as the primary measure of progress, and maintain simplicity (Beck et al. 2001).

Accordingly, since agile is a set of values and principles, it can be argued that agile provides a common foundation for making decisions effectively in software development. Abrahamsson et al. (2002) reported 8 different methods for software development based on agile values and principles. Out of those, Scrum is the most popular agile method among software developers (Rodríguez et al. 2012). Therefore, this research considers the scrum method to develop SGES. Some of the management practices and tools used in scrum are: (1) product backlog; (2) sprint; (3) sprint planning; (4) sprint review meeting; and (5) sprint retrospective meeting.

\section{DESIGN THINKING}

Design Thinking is an iterative and non-linear process for innovation which integrates human, business, and technological factors into problem forming, solving and design. Design Thinking consists of five major stages (Plattner et al. 2011). The first stage is to 'Empathize', which aims to fully understand the problem, stakeholders affected by the problem, relevant context, and its root causes as quickly as possible. To do this, the Design Thinking team can gather information in various ways, such as conducting searches, reviewing the literature, interviewing stakeholders and observing their behaviours. Based on analysis of information gathered, in the second stage ('Needfinding and benchmarking') the Design Thinking team can recognize and define the problem(s) faced by the stakeholders. 'Ideate' is the following stage, where the Design Thinking team produces different solutions that can solve any real problems identified in the previous stage. Brainstorming is a great way to generate user-centred solutions. The fourth stage is 'Prototype', which is defined by Houde and Hill (1997) as "any representation of a design idea, regardless of a medium". With the solution agreed by the team during the Ideate phase, a prototype is developed during this stage. The final stage is to 'Test', during which feedback about the prototype is collected from users. 
After the Test stage, and based on feedback received from users, the Design Thinking team must go back to previous stages with the aim of upgrading the prototype to one suitable for solving the problems faced by users.

\section{LEAN STARTUP}

Lean Stat-up is a "set of practices for helping entrepreneurs increase their odds of building a successful start-up. Core components of Lean Startup are the Minimum Viable Product (MVP) and the build-measure-learn loop" (Ries 2011). According to Ries (2011) the Minimum Viable Product (MVP) is "the version of the product built in the beginning with a minimum amount of effort and the least amount of development time". The aim of the MVP is to start the learning process, not to reach the end point of development. So, the concept of the MVP is key to the Lean Start-up approach and forces teams to focus on the most important features of a product that will bring value to the customer. Next, the Build-measure-learn loop aims to convert ideas into a product, measure responses of customers, and understand whether to pivot or proceed. Pivot is a type of change designed to assess a different fundamental hypothesis of the product.

\section{SERIOUS GAMES}

Games are purposefully designed to challenge the human imagination (Arnold et al. 2013). According to Abt (as cited in Michael and Chen 2006), in a game, players assume realistic roles, face problems, develop strategies, make decisions, and get fast feedback on the results of their actions. Michael and Chen (2006) defined serious games as "games in which education (in its various forms) is the primary goal, rather than entertainment". Also, they stated that games provide the opportunity to learn something without the cost of real-world consequences or errors. In addition to learning, serious games are used as an assessment tool in different fields, such as education and health, with higher validity and data capturing features (Kato and de Klerk 2017).

\section{DeSign SCIENCE ReSEARCH Methodology (DSRM)}

Peffers et al. (2007) presented a methodology called DSRM, which is an iterative process for design science research. DSRM begins with four possible research entry points: (1) problem centred initiation; (2) objective centred initiation; (3) design and development centred initiation; and (4) client centred initiation. Irrespective of the point of entry, the first stage is 'Problem Identification and Motivation', which aims to specify the research problem; the second is to justify the significance of the solution. Based on the problem definition, objectives for a feasible solution are developed. Objectives can be quantitative or qualitative. Also, knowledge of existing solutions to the defined problem is essential for this stage, and is known as 'Define objectives of a solution'. 'Design and Development' is the third stage, during which an artifact is developed as a solution idea. Models, methods, new properties of social, technical and/or informational resources are some of the examples of artifacts which can be embedded within a research contribution. The fourth stage is 'Demonstration', during which the applicability of the artifact is demonstrated. One or more instances of the problem must be able to be solved in this phase. This can be achieved by conducting experiments, case studies, proofs or other relevant activities. The fifth stage is 'Evaluation'. In this stage, the performance of the artifact is measured to solve the defined problem. Objectives of the research are compared with the actual performance of the artifact generated in the demonstration phase. For evaluation of the artifact, feedback from participants and functionalities of the artifact can 
be used. The final stage is 'Communication', in which the solution with its utility and novelty, and its impact on the researchers and industry practitioners, are communicated.

\section{INTEGRATION OF APM WITH DESIGN THINKING}

Häger et al. (2015) presented a model (DT@ Scrum) that integrates Design Thinking with Scrum, which is guided by APM. It comprises of three phases of operations. The first phase, Design thinking, focuses predominantly on Design Thinking activities; The second phase, Initial development, balances both design thinking and development activities. The third phase, Fully integrated, puts more emphasis on development. The aim of these phases was to enrich the planning of product development through innovative and usercentred ideas of Design Thinking in the beginning of the process which in turn results in a better understanding of the requirements of the software to be built.

\section{INTEGRATION OF APM, DESIGN THINKING AND LEAN STAT-UP}

Hildenbrand and Meyer (2012) linked Design Thinking and Lean Stat-up to APM in order to enhance software development for businesses. In their study, they emphasized the usefulness of Design Thinking to initiate the development process based on validated customer problems, and the importance of agile practices and lean thinking in the development of the best appropriate process. Grossman-Kahn and Rosensweig (2012) also proposed a design-led, multidisciplinary approach, the Nordstorm model, consisting of human-centred, collaborative, failure embracing, prototype-driven innovation mindsets and practices that link Design Thinking, Lean Stat-up, and APM. These authors demonstrated the scalability of that approach among cross-functional teams throughout development organisations. Paula and Araújo (2016) presented a new model by improving the Nordstorm model. According to this study, they proposed the followings: (1) User experience should be validated during the prototype phase with an interface that is closest to the final product; and (2) Design Thinking elements should be used throughout the entire development process. After performing a cross-case analysis of previous integrations between APM, Design Thinking and Lean Stat-up, Dobrigkeit and Paula (2017) presented another model called InnoDev, to improve the innovativeness in IT development. InnoDev consists of three phases: (1) Design Thinking; (2) Initial Development; and (3) Development. They argue that InnoDev is flexible enough for different business settings.

After analysing the features of the aforementioned process models, we can identify that all the Design Thinking phases, and elements of Lean Stat-up, such as MVP, buildmeasure-learn loop and pivot; and agile practices, such as scrum can be used to develop efficient software based on human-centred solutions. Therefore, we argue that the integration of the aforementioned management and development approaches can be used for the development of effective serious games. Also, serious games can be used as a tool for assessments incorporating user engagement without having real world consequences. Thus, serious games can be used with construction practitioners for developing CEs in a virtual environment without affecting construction operations' complex and dynamic nature. In addition, DSRM provides a methodological support to generate knowledge for $\mathrm{LC}$ research in relation to development of artifacts. 


\section{THEORETICAL FRAMEWORK TO SUPPORT SGES IN LC RESEARCH}

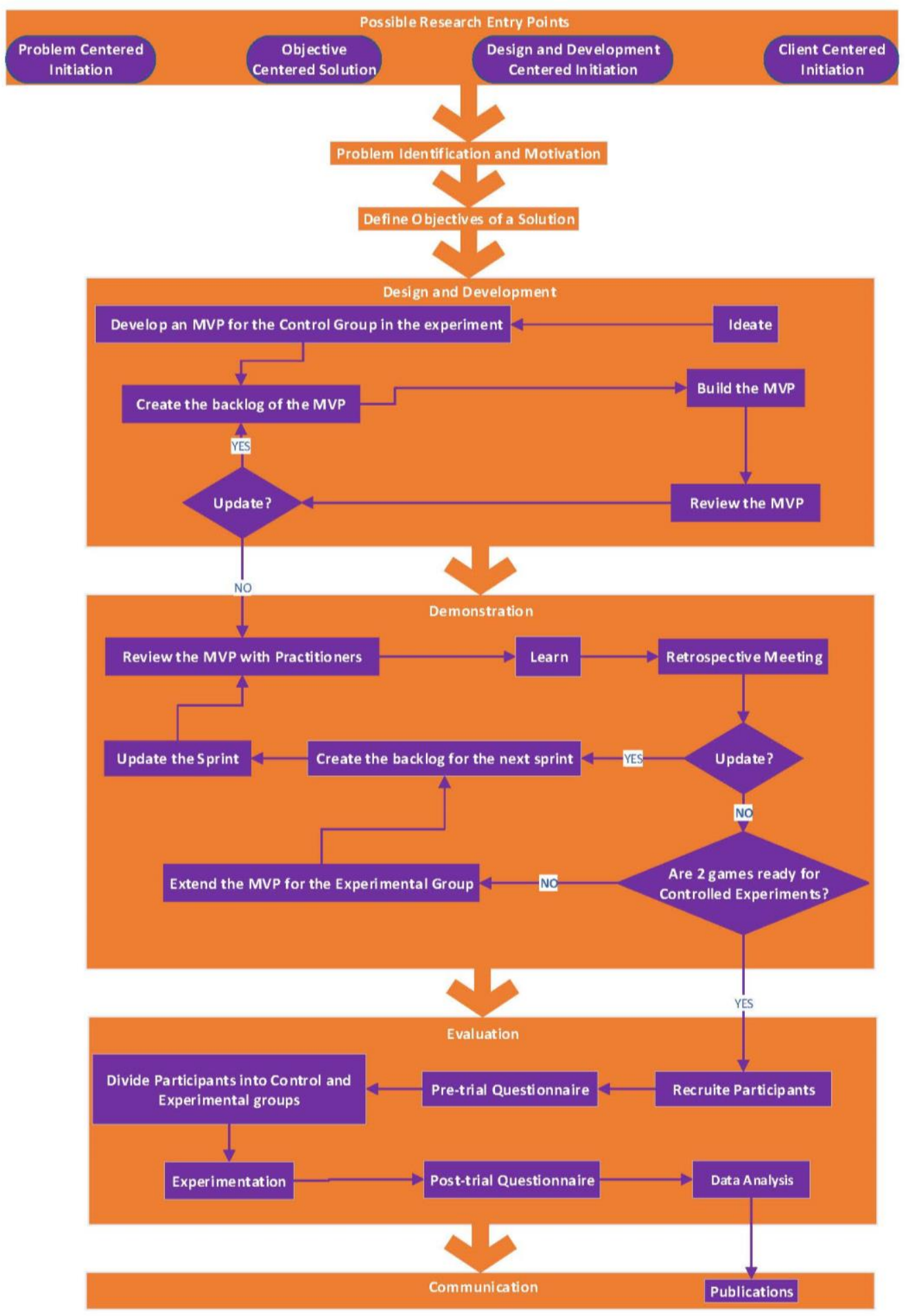

Figure 1: Conceptual integration framework for SGES

We argue that a framework that integrates DSRM, Design Thinking, Lean Stat-up and APM is useful in the development of a SGES, which is a novel methodology for 
experimenting artifacts, such as any designed object, including any design object, such as models, constructs, methods or new properties of technical, social or informational resources (Peffers et al. 2007), enriched with innovative solutions to real-world construction problems while also contributing to the knowledge of construction management. This approach, to a great extent, eliminates barriers to effectively testing hypotheses by providing an environment for controlled experiments in LC research.

The framework, shown in Figure 1, begins with the same four possible research entry points and the first two stages, as described in the DSRM (Peffers et al. 2007). Next, the experimental setting moves to the design and development stage. We argue that this stage should begin with the Ideate step in Design Thinking, during which a number of usercentred solutions can be generated through activities, such as brainstorming (Plattner et al. 2011). As the output of this step, we suggest the development of conceptual frameworks for two serious games that are used for CEs: (1) one game for the control group; and (2) the other game for the experimental group. We suggest demonstrating the applicability of the solution from the framework of the serious game played by the experimental group compared to the framework of the serious game played by the control group. The development of an MVP (Ries 2011) for the serious game for the players of the control group can then be initiated. As an MVP, we propose to develop the storyline, which presents the game content in a structured manner (Göbel and Mehm 2013), for that serious game. The storyline can be developed by establishing its product backlog, which is the work to be carried out to develop a product based on existing knowledge (Abrahamsson et al. 2002). After developing the storyline, it should then be reviewed by a team of domain experts in terms of usefulness, usability, credibility, desirability and value that influence the user experience. During the review, experts can propose further improvements of the MVP. Based on their suggestions, a new backlog can be created to upgrade the MVP. In this way, the initial storyline can be upgraded until the team of experts are satisfied. In order to make this process more efficient, researchers can use APM practices, i.e. scrum (Abrahamsson et al. 2002).

Subsequently, the demonstration stage is initiated, during which the interactive storyline, which was finalized by the domain experts, is further refined by exposing it to a team consisting of construction practitioners. We propose to use a tool, such as articulate storyline (Suppan et al. 2020), to perform the review process efficiently. Based on the review provided by the construction practitioners, the research team can learn how the existing storyline can be further improved iteratively, by applying the build-measurelearn loop suggested by (Ries 2011). Before starting the improvement process, the research team can organize a retrospective meeting which is a best practice of APM (Abrahamsson et al. 2002) to discuss how to improve the productivity of their serious game development process. Based on the outcome of the meeting, the research team can develop a backlog for further improvements of the interactive storyline. Accordingly, the next sprint of the storyline can be developed and demonstrated to the same team of construction practitioners. We suggest this sprint development process be repeated, buildmeasure-learn suggested by (Ries 2011) until the storyline is transformed into a serious game that can be used for the players of the control group of the experiment to the satisfaction of construction practitioners in terms of usefulness, usability, credibility, desirability and value that influence the user experience. After developing the serious game for the players of the control group, the same serious game can be further extended so that it is suitable for participants of the experimental group. We propose to achieve this by changing game elements relevant for the variable(s) to be tested during the $\mathrm{CE}$. These 
elements can be extracted from the conceptual framework designed for the experimental group in the Ideate step. To make the serious game ready for the experimental group, the same development approach which combines agile practices and lean start-up elements, as was done for the controlled group, can be applied.

The fourth stage of the experimental setting is evaluation, during which the $\mathrm{CE}$ is conducted. This stage begins with recruiting appropriate participants to play both serious games. After recruitment, the participants should be provided with a tutorial about the gaming environment to familiarize them with the game's software and hardware. Next, a pre-trial questionnaire should gather the participants' demographics and other researchrelated information. The participants should then be divided into the control group and experimental group Then, the experiment can be started during which each group plays one of the two games (that were finalized in the previous stages). After the experiment, another post-trial questionnaire should be distributed to both groups to gather data regarding their user experience. Also, in-game performance of participants should be gathered by analyzing video recordings of their gameplay. Finally, responses of both groups can be assessed using appropriate analytical techniques for testing the performance of the experimental group.

The final stage is communication, which was extracted by DSRM (Peffers et al. 2007). In this stage, the solution to the real-world construction problem, with its utility, novelty, and impact on both researchers and industry practitioners via the SGES can be communicated through publications.

For example, suppose a researcher wants to assess the impact of the pull system. In that case, this methodology can be applied by developing two serious games representing a construction project: one representing the pull system and the experimental case, while the other representing the push system and the control case. During the experiment, two games generate production costs, and those can be used to test a hypothesis that the pull system reduces the production cost over the push system, while controlling other compound effects. This is impossible with traditional methods, such as case studies.

\section{CONCLUSIONS}

We propose a new methodology for conducting CEs in LC research: SGESs. We present a framework for developing a SGES that integrates Design Thinking, Lean Stat-up, APM and DSRM and that was developed using knowledge from a review of previous research integrating subsets of Design Thinking, Lean Stat-up and APM. Integrating Design Thinking, SL and APM enables efficiently developed serious games to be embedded within DSRM, providing a SGES for LC researchers. This SGES framework can be utilised to solve more industry-specific, real-world problems faced by practitioners because SGESs allow for the participation of construction practitioners. Hence, the proposed SGES framework is an innovative contribution to LC knowledge and will also streamline further contributions by enabling CEs.

In order to begin the next step in developing this SGES framework, seven research questions have been formulated to garner feedback from the IGLC community: (1) How can game design elements, game dynamics and game mechanics be determined to develop useful serious games for experiments? (2) How can participants be chosen for such experiments? (3) How can the group sizes be quantified for the control and experimental groups? (4) How can participants be allocated to control and experimental groups? (5) What types of data should be gathered during the experiment? (6) What methods can be used to collect data during the experiments? (7) What analytical techniques can be used 
to test research hypotheses? Based on the feedback from IGLC, the SGES framework can be finalized so that it can be used to carry out CEs related to LC research.

\section{REFERENCES}

Abdelmegid, M. A., González, V. A., O’Sullivan, M., Walker, C. G., Poshdar, M., and Alarcón, L. F. (2019). "Establishing a Link Between the Last Planner System and Simulation: A Conceptual Framework." Proc. 27th Annual Conference of the International Group for Lean Construction (IGLC), 335-246.

AbouRizk, S., Halpin, D., Mohamed, Y., and Hermann, U. (2011). "Research in Modeling and Simulation for Improving Construction Engineering Operations." Journal of Construction Engineering and Management, 137(10), 843-852.

Abrahamsson, P., Salo, O., Ronkainen, J., and Warsta, J. (2002). Agile software development methods: Review and analysis. VTT Publications.

Arnold, S., Fujima, J., and Jantke, K. P. (2013). "Storyboarding Serious Games for Largescale Training Applications." Proceedings of the 5th International Conference on Computer Supported Education, SciTePress - Science and and Technology Publications, 651-655.

Beck, K., Beedle, M., Bennekum, A. van, Cockburn, A., Cunningham, W., Fowler, M., Grenning, J., Highsmith, J., Hunt, A., Jeffries, R., Kern, J., and Marick, B. (2001). Manifesto for Agile Software Development. The Agile Alliance.

Dobrigkeit, F., and De Paula, D. (2017). "The best of three worlds -The creation of innodev a software development approach that integrates design thinking, scrum and lean startup." Proceedings of the International Conference on Engineering Design, ICED, 8(DS87-8), 319-328.

Feng, Z., González, V. A., Mutch, C., Amor, R., and Cabrera-Guerrero, G. (2020). "Instructional mechanisms in immersive virtual reality serious games: Earthquake emergency training for children." Journal of Computer Assisted Learning, (October), $1-15$.

Göbel, S., and Mehm, F. (2013). "Personalized, Adaptive Digital Educational Games using Narrative Game-Based Learning Objects." K-12 Education, IGI Global, 281291.

González, V., Alarcón, L. F., Maturana, S., Mundaca, F., and Bustamante, J. (2010). "Improving Planning Reliability and Project Performance Using the Reliable Commitment Model." Journal of Construction Engineering and Management, Department of Civil and Environmental Engineering, Faculty of Engineering, University of Auckland, New Zealand, 136(10), 1129-1139.

Grossman-Kahn, B. Rosensweig, R. R. (2012). "SKIP THE SILVER BULLET: DRIVING INNOVATION THROUGH SMALL BETS AND DIVERSE PRACTICES." International Design Management Research Conference, BOSTON, 815-829.

Häger, F., Kowark, T., Krüger, J., Vetterli, C., Übernickel, F., and Uflacker, M. (2015). "DT@Scrum: Integrating Design Thinking with Software Development Processes." 263-289.

Hildenbrand, T., and Meyer, J. (2012). "Intertwining Lean and Design Thinking: Software Product Development from Empathy to Shipment." 217-237.

HOUDE, S., and HILL, C. (1997). "What do Prototypes Prototype?" Handbook of Human-Computer Interaction, Elsevier, 367-381. 
Kato, P., and de Klerk, S. (2017). "Serious Games for Assessment: Welcome to the Jungle." Journal of Applied Testing Technology, 18(December), 1-6.

Koskela, L. (2008). "Which kind of science is construction management?" Proceedings of IGLC16: 16th Annual Conference of the International Group for Lean Construction, 51-60.

Mateevitsi, V., Sfakianos, M., Lepouras, G., and Vassilakis, C. (2008). “A game-engine based virtual museum authoring and presentation system." Proceedings of the $3 \mathrm{rd}$ international conference on Digital Interactive Media in Entertainment and Arts DIMEA '08, ACM Press, New York, New York, USA, 451.

Michael, D. R., and Chen, S. (2006). Serious Games: Games that Educate, Train and Inform. Thomson Course Technology.

Montes, H., Hijon-Neira, R., Perez-Marin, D., and Montes, S. (2021). "Using an Online Serious Game to Teach Basic Programming Concepts and Facilitate Gameful Experiences for High School Students." IEEE Access, 9, 12567-12578.

Mostafa, S., Chileshe, N., and Abdelhamid, T. (2016). "Lean and agile integration within offsite construction using discrete event simulation." Construction Innovation, 16(4), 483-525.

de Paula, D. F. O., and Araújo, C. C. (2016). "Pet Empires: Combining Design Thinking, Lean Startup and Agile to Learn from Failure and Develop a Successful Game in an Undergraduate Environment." 30-34.

Peffers, K., Tuunanen, T., Rothenberger, M. A., and Chatterjee, S. (2007). "A Design Science Research Methodology for Information Systems Research." Journal of Management Information Systems, 24(3), 45-77.

Pelcin, A. (1997). "The Effect of Indentor Type on Flake Attributes: Evidence from a Controlled Experiment." Journal of Archaeological Science, 24(7), 613-621.

Plattner, H., In Meinel, C., \& In Leifer, L. (2011). Design Thinking. Design Thinking, (C. Meinel, L. Leifer, and H. Plattner, eds.), Springer Berlin Heidelberg, Berlin, Heidelberg.

Ries, E. (2011). The lean startup: How today's entrepreneurs use continuous innovation to create radically successful businesses. Crown Business, New York.

Rodríguez, P., Markkula, J., Oivo, M., and Turula, K. (2012). "Survey on agile and lean usage in finnish software industry." Proceedings of the ACM-IEEE international symposium on Empirical software engineering and measurement - ESEM '12, ACM Press, New York, New York, USA, 139.

Rumeser, D., and Emsley, M. (2019). "Can Serious Games Improve Project Management Decision Making Under Complexity?” Project Management Journal, 50(1), 23-39.

Sacks, R., Barak, R., Belaciano, B., Gurevich, U., and Pikas, E. (2013). "KanBIM workflow management system: Prototype implementation and field testing." Lean Construction Journal, 19-35.

Suppan, M., Catho, G., Robalo Nunes, T., Sauvan, V., Perez, M., Graf, C., Pittet, D., Harbarth, S., Abbas, M., and Suppan, L. (2020). "A Serious Game Designed to Promote Safe Behaviors Among Health Care Workers During the COVID-19 Pandemic: Development of 'Escape COVID-19."” JMIR Serious Games, 8(4), e24986.

Torp, O., Bølviken, T., Aslesen, S., Fritzsønn, L. P., Haagensen, Å., Lombardo, S., and Saltveit, T. (2018). "Is Integration of Uncertainty Management and the Last Planner System a Good Idea?" IGLC 2018 - Proceedings of the 26th Annual Conference of the International Group for Lean Construction: Evolving Lean Construction Towards Mature Production Management Across Cultures and Frontiers, 658-668. 